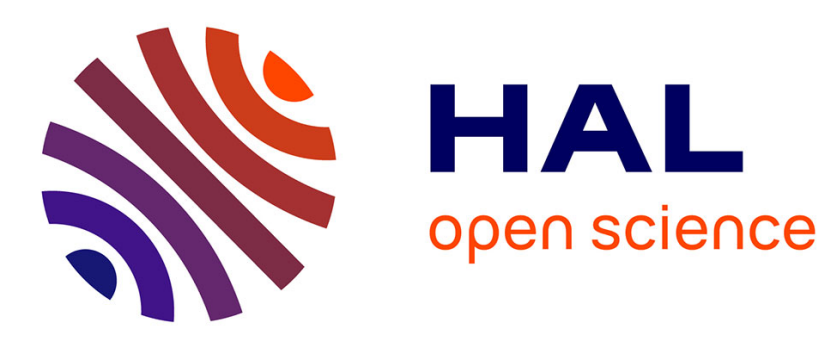

\title{
Medicalization and beyond: the social construction of insomnia and snoring in the news
}

Simon. J. Williams, Clive Seale, Sharon Boden, Pam Lowe, Deborah Lynn

Steinberg

\section{- To cite this version:}

Simon. J. Williams, Clive Seale, Sharon Boden, Pam Lowe, Deborah Lynn Steinberg. Medicalization and beyond: the social construction of insomnia and snoring in the news. Health, 2008, 12 (2), pp.251-268. 10.1177/1363459307086846 . hal-00571444

\section{HAL Id: hal-00571444 \\ https://hal.science/hal-00571444}

Submitted on 1 Mar 2011

HAL is a multi-disciplinary open access archive for the deposit and dissemination of scientific research documents, whether they are published or not. The documents may come from teaching and research institutions in France or abroad, or from public or private research centers.
L'archive ouverte pluridisciplinaire HAL, est destinée au dépôt et à la diffusion de documents scientifiques de niveau recherche, publiés ou non, émanant des établissements d'enseignement et de recherche français ou étrangers, des laboratoires publics ou privés. 
health: An Interdisciplinary Journal for the Social Study of Health,

Illness and Medicine

Copyright (C) 2008 SAGE Publications

(Los Angeles, London, New Delhi and Singapore) DOI: $10.1177 / 1363459307086846$

Medicalization and beyond:

Vol 12(2): 251-268

the social construction of

insomnia and snoring

in the news

\author{
Simon. J. Williams, Clive Seale, Sharon Boden, \\ Pam Lowe and Deborah Lynn Steinberg \\ University of Warwick, Brunel University, University of Keele, \\ Aston University and University of Warwick, $U K$
}

\begin{abstract}
A B S T R A C T What role do the media play in the medicalization of sleep problems? This article, based on a British Academy funded project, uses qualitative textual analysis to examine representations of insomnia and snoring in a large representative sample of newspaper articles taken from the UK national press from the mid-1980s to the present day. Constructed as 'common problems' in the population at large, insomnia and snoring we show are differentially located in terms of medicalizing - healthicizing discourses and debates. Our findings also suggest important differences in the gendered construction of these problems and in terms of tabloid and 'broadsheet' newspaper coverage of these issues. Newspaper constructions of sleep, it is concluded, are complex, depending on both the 'problem' and the paper in question.
\end{abstract}

KEYWORDS insomnia; media; medicalization; press; snoring

A D D R E S S Professor Simon J.Williams, Department of Sociology, University of Warwick, Coventry, CV4 7AL, UK. [e-mail: S.J.Williams@Warwick.ac.uk]

AC K N OW LED GEMEN T We are grateful to the British Academy for funding this project. We should also like to the thank Michael Traynor, editor of health: An Interdisciplinary Journal for the Social Study of Health, Illness and Medicine, and the anonymous referees of this article for their helpful comments.

\title{
Introduction
}

How are sleep 'problems' constructed in the British press? What light does this shed on relations between medicine and the media? And what does this tell us about the medicalization of sleep in contemporary society? These are some of the questions that this article seeks to address. Our study, in 
this respect, is located at the intersection of two newly emerging areas of sociological inquiry concerning sleep on the one hand and the media and health on the other.

If sleep, as Williams $(2002,2005)$ argues, is the latest chapter in the medicalization story, then what role do the media play? Two recent articles are suggestive on this front. Kroll-Smith, in a provocative article on popular media and 'excessive daytime sleepiness' (EDS), invites us to reconsider current accounts of medicine and medicalization, arguing that EDS is becoming a topic of popular consciousness and concern through a proliferation or profusion of media constructions of this 'problem' which largely bypass the traditional doctor-patient relationship. The media, on this reading, provide extra institutional, textual forms of authority cast in the rhetoric of medicine. There are signs moreover, Kroll-Smith (2003) contends, that EDS is now being constructed as a 'disease' or 'disorder' in its own right, rather than merely a symptom of some other underlying problem or pathology. Whether or not this represents 'disease mongering' on the part of the media is a moot point. Medicalization and disease mongering, to be sure, are far from synonymous. While there is undoubtedly an overlap in both view and substance of the two terms, medicalization is (ideally) a non-judgemental term, referring simply to the process of 'making medical', whereas disease mongering is more judgemental, implying a hankering after new diseases or expanding markets, in which the role of the pharmaceutical industry looms large (see, for example, Blech, 2006). ${ }^{1}$ To the extent, however, that the media, wittingly or unwittingly: (1) exaggerate the prevalence of disease; (2) encourage overdiagnosis, and/or: (3) overemphasize the benefits of treatment, then they may be guilty of disease mongering. Certainly this is the conclusion of Woloshin and Schwartz (2006) in their article on the social construction of the sleep problem, restless legs syndrome (RLS) in the American press. Media constructions of RLS, they argue, provide a prime example (on all three counts listed above) of how the media help 'make people sick' (see also Moynihan et al., 2002).

These issues, in turn, key into broader debates on the medicalization of society and the role of the media in the shifting fields of health and medicine. Conrad $(2005,2007)$, for example, has highlighted the shifting engines or drivers of medicalization over time, noting how doctors are no longer the primary drivers of medicalization. While the definitional centre of medicalization, he contends, still lies with medicine, other factors such as health care markets, consumers, biotechnology/pharmaceuticals, are now assuming centre stage in the medicalization of society. The media, from this viewpoint, may play a variety of roles in medicalization, depending on the particular case or problem in question, but are largely 'secondary' to these other key players or drivers of medicalization (Conrad, personal communication). That medicine may be 'put on trial' by the media, none the less, is amply demonstrated by Bury and Gabe (2006) in their work on television and medicine. Seale too, in his work on the media and health, points to a variety of roles the media may play, including the articulation of distrust in 
relation to professional authority and expertise, the elevation of ordinary consumer 'heroes' to a position of considerable authority, the generation of fears about disease as well as the construction of a variety of 'rewarding pleasures' (2004: x). Logical consistency, moreover, does not appear to be an overriding priority, given a variety of competing or contradictory forces, the different audiences and constituencies addressed and the way in which commercial and entertainment agendas (all too) frequently trump the promotion of sound knowledge.

This article makes a small contribution to these sociological debates on sleep, the media and medicalization through a critical exploration and examination of the social construction of two common sleep problems, insomnia and snoring, in the British news print media. As two of the most common sleep-related complaints, a comparative study of the social construction of insomnia and snoring provides a valuable opportunity to look in more depth and detail at the potentially variable role the media, or more specifically the British press, play in any such medicalization of sleep in contemporary society. To the extent moreover that insomnia is a problem of hyperarousal or sleeplessness which sufferers are painfully aware of and which primarily affects themselves ('I cannot sleep'), while snoring is something that happens during sleep, which the snorer qua sleeper remains unaware of but which may very well disturb others ('Your snoring kept me awake', or 'Your snoring woke me up'), then comparison of these two conditions raises some potentially interesting sociological and moral questions regarding the social construction of (un)consciousness, character, constitution, culpability and control.

\section{Researching sleep through the media: methodological matters}

This article is part of a broader study on the social construction of sleep in the British print news. The study, in this respect, was primarily concerned with the print media discourses and debates on sleep, rather than audience reception of and response to these messages, or the institutional arrangements involved in the production of news. Newspaper articles were sourced from the Lexis Nexis archival database. Our selection of five UK national newspaper texts (The Times, Guardian, Daily Mail, Daily Mirror, Sun) was influenced by knowledge of the circulation figures and readership profiles alongside sampling for contrasting tone, format and political orientation taken from Newspaper Marketing Agency (NMA) figures for 2005, at www. nmauk.co.uk). The Times and Guardian, for instance, are 'broadsheet' newspapers serving a readership comprised predominantly of highly educated, higher social class people (61 per cent and 61 per cent respectively according to NMA figures for 2005). ${ }^{2}$ They contrast with the Sun and Daily Mirror, tabloids serving a readership with a high proportion of lower social class people (35 per cent and 33 per cent respectively according to NMA figures for 2005), with the Daily Mirror's readership being markedly older 
than the Sun's (40 per cent of 55+ vs 27 per cent according to NMA figures for 2005). The Daily Mail serves a predominantly female (56\%) and older (49\% of 55+) readership with a class or educational profile that lies somewhat in between the tabloid versus 'broadsheet' poles (NMA figures for 2005). Together these five newspapers accounted for 76 per cent of the total circulation of UK national dailies in 2005 (NMA www.nmauk.co.uk).

Articles were retrieved from these five national newspapers (from the date of first loading on to the database until 31 August 2006), using search terms such as insomnia, insomniac, sleeplessness; snore, snorer, snoring, apnoea. As it was in-depth or major coverage we were most interested in, in this article at least, we used the 'three or more mentions' search criteria. ${ }^{3}$ This resulted in a total of 208 insomnia-related articles - divided more or less evenly between the 'broadsheets' (101) and the tabloids (107) and 358 snoring-related articles - with a higher number of tabloid hits (243) compared to the 'broadsheets' (115).

These articles were then scan read and sorted into broad thematic categories, ready for more detailed interpretive analysis. Articles that could not be readily coded in this way or that on further reading had little directly to do with sleep problems were also rejected at this stage. Furthermore, in-depth interpretive analysis was then conducted in which stories were compared and categorized in terms of the use of keywords and phrases, key developing issues and storylines, the use of 'experts' or survey/poll data, evidence of medicalization/disease mongering, how the reader was addressed/drawn into the piece, instructions on how the article should be read, any vocabulary with 'moral' and/or 'emotional' overtones within the selected articles, and how these articles constructed their subject matter.

\section{Can't sleep/won't sleep: stranded in 'limbo land'}

Given that insomnia is commonly considered a symptom of something else (rather than a sleep disorder in its own right), and given that it is commonly associated in the popular mind or imagination with worry, stress, anxiety and depression, it is perhaps not surprising to find a heavily psychologized discourse of insomnia in the press, which itself provides a novel window onto the social construction of subjectivity, sensibility and selfhood of sufferers themselves in the media. We see this expressed, for example, in a number of ways in our sample of newspaper coverage.

First, and perhaps most powerfully, this psychologized discourse is conveyed through the use of personalized stories and narratives, sometimes guest-written by people with insomnia themselves. Consider, for example, the following extract from a self-confessed chronic insomniac (Anita Sethi) in the Guardian (25 July 2005, 'Features' pages, G2: 'Real lives'):

$3 \mathrm{am}$

I write this as I am stranded in the limbo land between days. It is three o'clock in the morning and everything that is hidden in the background of daily life 
has come crawling forth: the tortuous ticking of the clocks, the thudding of my heartbeat, the tapping away of the keyboard, measuring out time, blood, words. These are the loneliest hours in the universe, the wasteland of time ... It feels like I am the only person left in the world awake. (emphasis added)

Far from being 'alone', however, the author proceeds to note: 'there are at least 3 million people in Britain tossing and turning, eyes burning, restlessly pacing through their houses with unruly consciousness'.

Findings from the latest polls and surveys are then reported, in order to highlight the extent of the 'problem', including a study called 'Insomniac Britain' by the Future Foundation and British Association of Counselling and Psychotherapy, which revealed that ' $27 \%$ of the population -12 million people - have at least three bad nights of sleep a week, with $63 \%$ suffering from at least one bad night'. 'The problem seems to be worsening,' Sethi notes, 'the study found that almost one in four people were finding it increasingly difficult to sleep well.'

Another variant on this theme, particularly in the tabloids, was the use of two or more case studies, usually women, to illustrate the trials and tribulations of insomnia, often in the context of more general pieces on sleep. The Daily Mirror (21 December 1998), for example, in a headline that claims to reveal some 'eye-opening bedtime facts', zooms in on the problems of insomnia, noting how 'chronic insomnia can last for years', and how 'intermittent insomnia can be triggered by anxieties and crises'. Insomnia, the article proclaims, is 'boring and uncomfortable, and it can affect your daily activities, work and relationships'. Two case studies are then presented: the first a TV extra, Deborah Grossman, 43 from Sale, Cheshire, who apparently 'hasn't had a decent night's sleep since she married her husband Alan 14 years ago'; the second, a college tutor, Jane Famous, 41 , from North London, who, 'despite spending $£ 15,000$ on remedies and treatments', still 'can't sleep for more than half an hour at a time'. 'I used to think insomnia was a physical condition - that some chemicals in my body had got mixed up,' Jane says. 'But now I realise it is something much deeper and emotional, going back to my childhood' (emphasis added). 'It's true,' she concludes, having listed a catalogue of woes associated with her insomnia, 'that sleep really is the secret to a happy life.'

This particular psychological reading or rendition of insomnia was in turn reinforced through newspaper coverage of the latest findings from various experimental studies conducted within the sleep science community, again usually by psychologists, on the most efficacious way to rid oneself of this 'ailment', 'ill' or 'curse'. Cognitive behaviour therapy (CBT), in this respect, featured prominently in both serious and tabloid papers as the treatment of choice. The Times, for example, in a piece entitled 'Sleep quality and sleeplessness' (23 September 2005), cited a recent review in The Lancet, that 'counselling and psychological help are more effective than pills at tackling chronic insomnia'. Research, moreover, the article continues, has suggested that 'just two hours of cognitive behaviour therapy (CBT) was 
able to cure insomnia by encouraging patients to acknowledge the stress that was preventing them from sleeping, then helping them to develop ways of dealing with it'.

An implicit if not explicit moral reference point here, in much of this coverage, was that people with insomnia had 'poor psychological habits' and were as such 'their own worst enemies', frequently obsessing about their sleep and exaggerating the extent of their problems. This in turn served to strengthen further the rationale for CBTs and other forms of psychological intervention as a fast, effective, way to 'save insomniacs from themselves'.

It is perhaps unsurprising in this context, given previous controversy and criticism over sleeping tablets (Abraham, 1999; Gabe and Bury, 1996), that this sample of newspaper coverage usually took a strong anti-drugs line on the treatment of insomnia: one that appeared to echo or amplify prevailing opinion within the medical and sleep science community. Doctors indeed were portrayed as being reluctant to prescribe sleeping tablets as anything other than a short-term measure for insomnia. The Sun (14 August 2003: 'Medicine man: Health' section), for example, in an article entitled 'Get a good night's sleep without pills' by Dr Keith Hopcroft (medical editor of Men's Health magazine and co-author of A bloke's diagnose it yourself guide to health) opens with a supposedly typical doctor-patient exchange:

'The thing is doc,' he says, 'I'm having trouble sleeping.'

I know what's coming next - a sheepish look, then: 'So I wondered if I could have some sleeping pills?'

My answer is nearly always the same. Sorry, but no. Because sleepers [sic] don't get to the root of the trouble. Also they can have side effects, like making you drowsy in the day. And they can be addictive.

The moral valence here is clearly tilted in favour of the responsible doctor, who 'knows best', again reinforcing the notion that, as far as insomnia is concerned, people really are their own worst enemies. This in turn is buttressed through other stories of patients complaining that it is now increasingly difficult to get sleeping pills from their doctors.

These concerns and cautions also extended to press coverage of other proposed pharmacological treatments for insomnia, both now and in the future. The Times (15 October 2003: 'Features' section), for instance, informs its readers that experts believe that 'half the people with insomnia' suffer from a 'chemical deficiency' which makes them 'chronically anxious by day and have disrupted sleep by night'. These findings, the article comments, have proved to be 'of interest to the pharmaceutical industry', noting how; 'a wave of new medications designed to eliminate anxiety and sleeplessness, based on the new understanding of brain chemicals, is due to arrive on the market soon'. But British experts, readers are informed, are 'divided over the benefits of drugs that promise to replace Valium-style benzodiazepines'. Again this provides a vehicle for the article to cycle back to the merits of 
CBTs and other techniques designed to relax sufferers. 'It is this ingrained habit of worrying - the "negative thinking style",' Dr Helen Nightingale (a chartered psychologist) is quoted as saying, 'that causes the imbalance of brain chemicals, and it is this that needs to be addressed.'

Cognitive behaviour therapies and other psychological-based interventions were not, however, the only proposed remedies on offer in the press. Newspapers, indeed, were replete with general tips, advice and guidance on how to sleep 'well' or how to get a 'good night's sleep', particularly the tabloids, including coverage of the latest books and guides (such as Learn to sleep well by sleep expert Professor Chris Idzikowski, and Stop counting sheep! - a self-help book for insomniacs by Dr Paul Clayton) and other alternative remedies and relaxation techniques, from meditation to feng sui. The Sun (20 May 2004), for example, in a typically playful headline ' 7 great sleep aidszzz', asks its readers: 'Having trouble nodding off?' 'Plenty of products claim to help you sleep,' the article notes, but 'you need the right one for you.' Dr Carol Cooper is then called upon to give her expert opinion on seven sleep aids (earplugs, blackout curtains, milky drinks, melatonin, herbal supplements, aromatherapy bath soaks and light boxes), with costs compared and each product rated for the reader.

Variants on this coverage, however, were also apparent in the more serious papers, including an article in the Guardian (13 April 1998: Features pages) where a variety of advice is offered from readers of the paper themselves in relation to an anonymous if not fictitious sufferer's call for help. 'I've always been a bit of an insomniac,' the headline proclaims,

but it's got worse over the past couple of years (new flat, husband, cats). I've tried everything, from milky drinks to herbal remedies and hypnotherapy. I've even spent a month getting up at $8 \mathrm{am}$ at weekends as well as during the week to 'stabilise' my sleep pattern.

'Think of black velvet,' writes one reader, in response to this conundrum. 'Ignore it,' writes another. A catalogue of further advice is then served up from readers, including listening to the radio, feng shui, exercise, cannabis, melatonin, change of diet, change of job and a change of viewpoint based on an 'acceptance' of one's insomnia and the use of this 'extra time' positively and creatively to 'work or potter about quietly'.

There is precious little in this newspaper coverage, then, that portrays insomnia in anything other than psychological terms. Occasional stories about the problem of insomnia for asthmatics, post-menopausal women who are not taking HRT or the elderly do little to dispel this impression, or convey an alternative 'truth' about this complaint. The 'locus' of insomnia, it seems, as conveyed through these expert discourses and echoed/amplified through the media, is primarily the sufferer's 'psyche', the 'solution' to which is best achieved through cognitive means and/or other forms of self-help rather than doctors or drugs. At best the 'good' doctor is reduced here to mere conduit or referral pathway en route to other more 'appropriate' 
and 'effective' (read psychological) interventions, while the 'bad' doctor is criticized or castigated (as in the past) for reaching too readily for the prescription pad.

\section{'Trouble in snore': raising the roof and choking to death}

Compared to the trials and tribulations of insomnia, both snoring and the snorer are portrayed by the press in very different terms. A common point of reference here, in many opening storylines, is to treat snoring/the snorer in somewhat jocular or jovial terms, including humorous comparisons between snoring and other loud or unpleasant noises, and references to longsuffering partners, usually women and wives, and other family members. An article in The Times (21 August 2003: 'Features' section), for example, opens in the following fashion:

These are terrible things to endure, this snoring, or the fidgeting all night because of restless feet, or banging your head like a hammer on the pillow while you dream. But as Nicholas O'Dwyen's film 'Sleeping Together' (BBC Two), underlined, it is the snorers' partners who do most of the suffering. It is the wives (and snoring like the Queen Mary's funnel is mostly a male affliction) who weave their way through each night like pick pockets, nimbly stealing a few minutes of sleep here and there in the gaps between their husbands' snores. (emphasis added)

To call these sounds 'snores', however, the article continues: 'is like calling the Niagara Falls a water feature. These are the snores that rouse the Richter scale. Properly harnessed to a bullhorn they could serve useful civic duties, such as warning whole communities of impending hurricanes.'

The Sun (11 April 2002: 'Health' section) too, in its own inimitable style, asks its readers:

Do you wake up unrefreshed with a bruised feeling on one side of your chest?

Then you're a snorer if your long-suffering partner has spent most of the night digging you in the ribs.

And no wonder: In surveys, the noise of male snoring has been likened to a pregnant rhinoceros, an express train and a chainsaw which sounds amusing, until you discover that the partners of snorers lose about an hour's sleep each night and that a quarter of couples say it affects their sex lives. At best it's a major nuisance. At worst it's divorce.

References here to the gendered nature of snoring and its impact on relationships, including sex lives, were common. This in turn was occasionally followed by coverage of various non-medical remedies or solutions to these problems, from the stitching of a tennis ball into the back of tight-fitting pyjamas (e.g. The Times, 25 June 1998) or the use of two tennis balls in a reverse bra worn on the back rather than the front, to sleeping in separate bedrooms - something, according to various profiled couples or cases, which also seemed to improve their sex lives. 
Frequently, however, in these and other storylines, a move or slide is evident from this portrayal of snoring in the main as a problem for others (particularly long-suffering bed partners) to the potential problems or pathologies underpinning it, particularly in cases of heavy snoring, hence the risks to snorers themselves. An article in The Times (21 November 1998), for example, notes that: 'While snoring has long been seen as a passion dampener, it is only recently that it has emerged as a potential killer' (emphasis added). Statistics are then quoted which suggest that 'you are six times more likely to nap at the wheel if you are heavy snorer'. In those who suffer from obstructive sleep apnoea (OSA), moreover, the article continues,

the airways become blocked, and they stop breathing for anything up to a minute during sleep. Some researchers suggest that this may cause a reduction in bloodflow to the brain and increases a risk of high-blood pressure, and even heart attack and stroke.

Conveying and amplifying concerns within the sleep science and medicine community, then, the emphasis here is usually placed upon the need to take snoring seriously, particularly heavy snoring, not least in terms of the potential underlying problem or pathology of OSA, thereby recasting the complaint as a 'serious' medical matter; one that stands in need of far greater public attention, given the risks it entails both to self and others. An advice column by Miriam Stoppard (resident doctor for the Daily Mirror) entitled 'Trouble in snore' (10 November 1999), for instance, noted that while snoring is often treated as a joke, it 'could be a warning sign that we should take more notice of'. Several things, she explains, make us more likely to snore, including obstruction by the tongue if it drops to the back of the mouth, small or collapsing nostrils, large floppy soft palate or uvula, and in children, enlarged adenoids and mouth breathing. 'Most causes of snoring,' the reader is told, are 'easily remedied, and there is a good chance that simple treatment or a change in lifestyle will significantly improve things.' But 'other causes', Stoppard stresses, are more complex and need specialist investigation and treatment. The article then raises the question as to whether or not snoring is dangerous, answering that 'snoring, itself, isn't serious but it can be a symptom of a more serious sleep disorder, sleep apnoea, in which the snorer stops breathing several times an hour during sleep'. 'The point', the article continues:

....is that people with sleep apnoea are prone to irregular heart beats, even possibly heart attacks. The most vulnerable person ... is a man over the age of 45 or a woman who's gone through the menopause and isn't taking hormone replacement therapy. So if you're a middle aged snorer, ask your doctor to check you over.

'Several hospitals,' the reader is told, 'have sleep apnoea and snoring clinics which can investigate the causes of snoring and diagnose sleep apnoea. Your GP can refer you for specialist tests to diagnose the cause of your snoring and recommend treatment.' Various treatments are then 
listed for snoring, including (new) surgical procedures for snorers who have obstructions of the mouth, nose and throat and, in cases of significant obstructive sleep apnoea, continuous positive airways pressure (CPAP). Readers are also invited to write in with their own 'favourite remedies' for snoring, the best of which Stoppard promises to 'publish on my page'.

As with insomnia, some of these discussions of snoring and sleep apnoea are embedded in more general articles on sleep problems, and advice on how to deal with them. Occasionally, however, insomnia and snoring are explicitly juxtaposed in a dedicated storyline devoted to both conditions. A Guardian article (4 October 1988), for example, written by sleep expert Professor Jim Horne for the 'Futures' section of the paper, bears the attention-grabbing headline: 'Flicker of nightly wakes - Insomniacs may get more sleep than they think whereas heavy snorers get less'. Insomniacs, Horne explains:

often sleep reasonably well but report being awake a lot, whereas heavy snorers wake up many times but believe they have slept well. The acid test for badly disturbed sleep is excessive sleepiness the following day. It is heavy snorers who usually suffer this not the insomniac.

Family history and genetics also comes into the picture here. The Guardian (15 December 1999: 'Home' pages), for example, in an article by the health correspondent entitled 'Sleep disorder link to family snoring habits', reports that:

Snoring may run in families, according to lung specialists who told a conference
yesterday that they think they are on the trail of a gene responsible for the anti-
social habit ... 'We have made real progress in identifying a family link to sleep
apnoea,' said Simon Wharton who reported to the British Thoracic Society's
conference yesterday ... 'We now want to conduct DNA tests to pinpoint the
gene that boosts the likelihood of a person developing this condition.'

Similarly, The Times (11 April 2006: 'Home News' section) ran a story 'Like father like son: Why snoring runs in families', in which the reader is informed that: 'A child whose mother or father snores is three times more likely to be a noisy sleeper, research suggests.' It is not simply the clinical problems of this condition, however, which are being picked up and reported upon here by the press. Rather, in keeping with the more general debates outlined earlier on the costs and consequences of sleep deprivation/sleepiness in contemporary society, the concern here is with the risks to public health and safety, particularly road accidents. The Guardian (17 February 2001: 'Weekend' pages), for example, in a general article on sleep, notes how 'in many cases' of death on the roads:

the culprits are people who can't sleep because either they or their partner has a condition called apnoea - obstruction of breathing passages that causes them to snore or even partially suffocate. The British Snoring and Sleep Apnoea Association claims that there are around 3.5 million sufferers and suffering partners 
in the UK alone, many of them undiagnosed. Snoring is too easily dismissed as a joke, it says. But when people don't sleep, the consequences can be tragic.

A particular group singled out for sustained press attention, in this respect (itself a reflection of the clinical profile and epidemiology of this condition), are obese middle-aged male snorers, particularly those working in the transportation industry as a significant 'at risk' group. Another article in the Guardian (25 August 1989), for instance, entitled 'Dangers in the night' again by Professor Jim Horne, informs readers that: 'About half the sufferers [of OSA] are obese, as the fat around the throat, together with sleeping on the back, adds to the throat's collapse.' Similarly, a report in The Times (20 May 1995) bearing the headline 'Most truckers facing sleep risk', informs readers that: 'American sleep scientists [at Stanford University Medical School] have diagnosed sleep apnoea, a condition that interrupts sleep causing severe fatigue, among $78 \%$ of truck drivers.' To the extent, however, that this is a medically recognized condition that many sufferers remain 'unaware of', the guiding scheme of imagery here has less to do with the morally culpable agent than the innocent or unwitting victim of a potentially life-threatening, tragic, condition. All that is required on the part of readers who think they may be suffering from this condition, indeed, is to go to the doctor and take it from there - though failure to do so, of course, again brings moral culpability in through the back door.

Children are also now being drawn into the media spotlight as another potential 'at risk' group in relation to this condition, with (heavy) snoring again flagged as a prime sign or symptom of concern. In contrast to the obese middle-aged man or the 'at risk' lorry driver, however, the concern here has less to do with risks to public safety than with matters of health and education, mood and behaviour. The Times (11 October 2004: 'Features' section), for example, reports that:

Children who have difficulty breathing during sleep score lower in intelligence, memory and cognitive tests than other children of their age, says a study in the American Journal of Pediatrics. The study found that one-year-olds who experienced brief breathing pauses (apnoea) or slow heart rates during sleep scored lower than other infants. A second study made a similar finding in relation to five-year-olds.

The Daily Mirror (21 October 2004), in similar fashion, informs its readers that: 'Children who regularly snore are more likely to have emotional and behavioural problems, new research shows.'

These reported links between (heavy) snoring and obstructive sleep apnoea, moreover, in keeping with broader debates on the costs and consequences of sleep deprivation in contemporary society, are now being used to reframe debates on hyperactive children/children with ADHD. Links between childhood obesity, snoring and sleep apnoea are also now being picked up and commented upon in the press as a further cause for concern. We see this very clearly, for example, in an article in the Sun (3 June 2004) 
with the headline, 'Fat kids can die in sleep'. 'Fat Scots kids', the article proclaims:

are being sent home from hospital with ventilators - to stop them dying in their sleep. The overweight youngsters' fat can stop them breathing during the night so they are hooked up to machines until they slim down. Glasgow's Yorkhill Sick Kid's Hospital is giving patients a mask connected to a Continuous Positive Airway Pressure Pump (CPAP).

While these two groups (middle-aged, obese, male snorers, and obese snoring children) were singled out for particular media attention, occasional articles were also devoted to the related risk of central sleep apnoea as we get older. The Times (9 August 2005: 'Home news' section), for example, in an article entitled 'Why death is more likely to strike while you sleep' by the Science Correspondent, informs the reader how 'central sleep apnoea is most common among the over 65s', and that it 'often causes death when the person stops breathing but fails to wake up'. 'Even if the person is aroused,' the article notes, 'the lack of oxygen can trigger heart failure or stroke.'

A final significant theme in this press coverage of snoring and sleep apnoea concerned issues of treatment. This was manifest in two main ways. First, through personal stories and case studies of people's experiences of treatment, particularly the use of CPAP machines. The Times (21 November 1998), for example, in the storyline noted earlier about the journalist whose father 'snored light a freight train', notes how:

the treatment, as my father discovered, was to sleep with a Continuous Positive Airway Pressure machine - shaped like a small vacuum cleaner, complete with Darth Vadar-like mask and tube. Against his will he wore it, producing good, if not immediate, results. 'At first I thought I was suffocating,' he says. 'But after a while it became easier and I've got a lot more energy now.'

The Daily Mail (26 March 2002) also, in a headline entitled, 'A mask that keeps me alive as I sleep', tells the story of Brian Arthur, a former bus driver and sufferer of obstructive sleep apnoea who, readers are told, was entered into a clinical trial at the Sleep Unit at Oxford's Churchill Hospital, where patients were treated with one of two different pressures of nasal Continuous Positive Airways Pressure (nCPAP). During the trial, the reader is told, Brian remained unaware if his treatment was therapeutic or a dummy version. 'The machine was calibrated according to a computer and my blood pressure was checked at regular intervals,' he reports.

It was only at the end of the trial that I found out my blood pressure had come down significantly more than it did on the medication [for high blood pressure] alone. It is wonderful. The doctors have done a great job.

The second main way in which treatment issues were raised in this press coverage concerned stories regarding the inadequacies of current NHS provision for the treatment of this and, indeed, other sleep disorders. The Daily Mirror (19 August 2004), for example, in a short article entitled 
'2 year wait for sleep help', highlights the fact that: 'People suffering from a disorder [sleep apnoea] that can cause them to fall asleep while driving have to wait up to two years for treatment.' Professor Walter McNicholas from St Vincent's Hospital is then drawn into the storyline, stating that 'the resources to treat the illness are not up to standard and there is a shortage of trained technicians'. The British Snoring and Sleep Apnoea Association, in this respect, is frequently mentioned as an organization that is: 'campaigning for snoring and its associated disorders to be taken more seriously' (The Times, 21 November 1998). Certainly the UK is less well served in terms of sleep clinics and laboratories than the USA. Yet, there is more than a hint of criticism here (on the part of certain British sleep experts at least), that the USA is somewhat 'over' or 'too well' served with sleep clinics, thanks to the enterprising efforts of sleep medics and a much-publicized obsession with sleep deprivation.

Compared to insomnia then, snoring, when translated as a symptom of OSA, is a condition that is steadily or readily constructed in the news as a medical problem: construed not simply as a problem for sufferers and their families, but for the public at large who are daily being put 'at risk' through the potentially (fatal) accidents this condition may engender. To the extent, moreover, that OSA is now serving to reconfigure or reframe debates about other conditions such as ADHD and (childhood) obesity, then this is clearly an expanding diagnostic category, though not of course one of the media's own making.

\section{Discussion and concluding remarks}

What then, returning to the questions posed at the very beginning of this article, does all this tell us about the social construction of insomnia and snoring in the British press, and what light does it shed on the medicalization of sleep in particular and relations between medicine and the media in general?

Concerning the first of these questions, our findings suggest a contrasting picture regarding the social construction of insomnia and snoring in the news. Insomnia, as we have seen, is portrayed, constructed and understood through a 'psychologized' discourse, couched in terms of stress and anxiety, worry and depression, with favoured treatments ranging from basic principles of 'good' sleep hygiene (e.g. lifestyle issues, regular sleep schedules, correct bedroom environment, etc.), through cognitive behaviour therapy, to other alternative remedies and forms of self-help. Sleeping pills or tablets, as such, often get a bad press: construed as very much a 'last resort' or a 'short-term measure', given the fact that insomnia is now viewed (within the sleep science/medicine community itself) as a symptom rather than a pathology or disorder in its own right. Insomnia sufferers, moreover, underlining this particular reading of the problem, are often constructed through discourses, which while sympathetic to their plight, none the less 
emphasize personal responsibility. People with insomnia, as such, are often seen to be 'their own worst enemies' when it comes to their sleep, with 'poor psychological habits' and a tendency to 'exaggerate' their plight: a problem to themselves in other words. The nocturnal recordings of the sleep laboratory, as such, become the ultimate benchmark against which these sufferers' testimonies are judged, though few sufferers of course ever make it to the sleep lab. People with insomnia, in short, are fully and painfully aware of their malaise, but this it seems is part of the problem.

Newspaper coverage of snoring, in contrast, provides a different picture. Initial constructions of snoring as a common complaint, which long-suffering partners and families have stoically (or not so stoically perhaps) to put up with and/or manage as best they can, frequently give way to alarm calls of potential underlying pathology in the shape or guise of OSA. Coverage, as such, frequently draws on members of the sleep science and medical communities (through quotes, specially authored pieces, advice columns, etc.) in order to: (1) alert people to the dangers and risk of this underlying condition, both for sufferers (e.g. increased risk of stroke, coronary heart disease) and the public at large (through accidents, etc.); and (2) highlight appropriate treatment options, via sleep clinics, the CPAP machine and the like. Headlines such as 'Sleep can kill', 'Trouble in snore' and 'Do I snore or do I have sleep apnoea?' serve to convey to the reader a sense of concern or alarm about the potential problems or pathologies underpinning this seemingly mundane complaint. The snorer, construed and constructed in this way, is characterized in predominantly middle-aged terms, particularly through coverage of the dangers and risks of obese, sleepy, lorry drivers who remain unaware of their condition. While snoring, therefore, may well be a problem for snorers themselves, in cases of (un)diagnosed obstructive sleep apnoea and associated disorders, it is also constructed as a problem for others, both immediate or intimate others and the public at large. To the extent, moreover, that these discourses are serving to reconfigure or reframe debates about other conditions, particularly (childhood) obesity and ADHD, then what we see here is a further series of claims-making around the problems of snoring and OSA. These concerns in turn resonate with wider debates over the obesity 'crisis' and existing ideas, in cases such as the drowsy 'lorry driver', or 'dangerous' working-class bodies.

Questions regarding the social construction of 'control' also arise at this point in relation to the two conditions studied. At one level, of course, both insomnia and snoring may be regarded as behaviours over which the individual has little or no control: 'I want to sleep but I can't', or 'I can't help snoring.' To the extent, however, that people with insomnia are constructed as 'their own worst enemies', exaggerating their plight and demonstrating 'poor psychological habits', then personal responsibility creeps in through the back door. Changing one's 'habits', moreover, with or without the aid of an expert, suggests that insomnia is indeed something we can control. Even in the case of snoring, moreover, the onus of responsibility is still firmly 
placed on the individual to do something about it, if not for themselves then for others. Snoring, in this respect, may be likened to health and moral discourses surrounding secondhand smoke to the extent that steps are taken to control or prevent it because it affects others, although we cannot of course ban snoring like we can ban smoking in public places. ${ }^{4}$

A further important dimension to the picture here, however, concerns the social construction of sufferers of these complaints in gendered terms. A feminized discourse, for example, is clearly evident in newspaper constructions of insomnia sufferers, not simply through the common use of female case studies or the citing of evidence of a female excess of insomnia, but also through other gendered associations and stereotypes which underline the psychological nature of this complaint and reinforce notions of the 'emotional' woman and the 'unemotional' man. Male insomniacs, in this respect, may themselves be portrayed in feminized terms, albeit one mediated, for males and females alike, through discourses of stress both at home and in the workplace. A masculinized discourse, in contrast, is clearly evident in the case of the snorer. Snoring, indeed, is typically portrayed as a male complaint, whether 'naturalized', 'satirized' or 'pathologized': a complaint, to repeat, embodied in the figure of the overweight middle-aged man whose collar size exceeds 17 inches. The stigmatizing consequences of snoring, moreover, are themselves heavily gendered, with differing symbolic consequences and connotations for men and women. Snoring, as such, plays a dual role in the construction of gender identities, confirming men's masculinity and calling into question women's femininity.

So what then does all this tell us about relations between medicine, the media and the medicalization of sleep?

It is snoring, perhaps, which provides the most obvious case of a medicalized or medicalizing discourse in the press, though primarily as we have seen (in the case of heavy snoring) through the vehicle of obstructive sleep apnoea. The case of insomnia, however, is less clear-cut and more complex. Insomnia, to be sure, has long been recognized within the history of medicine as a pervasive problem, but is now commonly regarded as a symptom rather than a disease in its own right; one which does not easily or readily fit into a medicalized frame of reference. These tensions are clearly evident in our sample of newspaper coverage of insomnia. To the degree this media coverage evinces an 'anti-drug' line on the treatment of insomnia, then this may suggest a non-medicalizing, or at the very least an 'anti-pharmaceutical', discourse. To the degree, however, that psychological discourses are involved in which notions of stress, anxiety, worry and depression are emphasized, then this press coverage reflects and reinforces a 'therapeutic culture of self', including expert-led techniques of 'self-inspection' and 'self-reflection' which seek, in Rose's (1990) terms, to 'govern the soul' with ever increasing precision through 'therapies of freedom'. The social dimensions of insomnia, in this respect, are read or represented through a largely psychological prism which itself personalizes 
the political. These media discourses of insomnia, moreover, as we have seen, are largely 'derivative', reporting, rehearsing, reflecting and reproducing prevailing views and opinions, advice and guidance, truth and wisdom, within the sleep science/sleep medicine community, much of which is North American in origin.

All in all, then, this newspaper coverage appears to straddle themes pertaining to both the medicalization and the healthicization of sleep: the former translating sleep into a 'medical' matter through the language of disease and disorder, the latter emphasizing the importance of sleep for health, well-being and public safety as an obligation of every responsible citizen through appropriate lifestyle choices and principles of 'good' sleep hygiene (see Williams, 2005). Representations of psychological expertise, in this respect, lie ambiguously across these two domains, part and parcel, to repeat, of a therapeutic culture of self, couched in the rhetoric of selfinspection and self-improvement. These findings, moreover, strengthen our conviction, articulated elsewhere (Seale et al., 2007, Williams, 2003), that so-called 'personalized' strategies of sleep management (Hislop and Arber, 2003a, 2003b) are not that 'personalized' in a media-saturated age such as ours.

There were also notable differences, as one might expect, between the 'broadsheets' and the tabloids in terms of styles and content of coverage: the former conveying a more scientific style of reportage to their readers, the latter framing things in much more personalized ways addressed directly to the reader, including (sensationalized) stories of things that had happened to people such as accidents or other weird and wonderful events while asleep or sleepy. The tabloid use of terms such as 'dozy', 'snooze', 'booze', 'fat' or 'fatties', and reference to sleep experts as 'docs' 'profs' or 'boffins', further underlines these differences, thereby suggesting a varied and complex picture of newspaper coverage depending on the type of paper in question (see also Seale et al., 2007).

As for Kroll-Smith's (2003) contentions on medicalization and the media, our findings both confirm and qualify his arguments in important ways. Certainly Kroll-Smith is right to highlight the importance of extra institutional, textually mediated forms of authority and expertise in contemporary society, which while cast in the rhetoric of medicine none the less bypass the traditional doctor-patient relationship altogether. To the extent, however, that the media are still by and large conveying and relaying, amplifying and disseminating concerns and discourses circulating within the sleep science and sleep medicine communities, with or without the backing of the pharmaceutical industry, then caution is needed here in any such interpretation. The traditional doctor-patient relationship, moreover, is itself sometimes used as a template or framing device within these media storylines, with patients often called upon or encouraged to visit their doctor. 
Sleep, to conclude, is indeed another chapter in the medicalization story, one in which the media may play a variety of roles depending on the problem in question. This in turn suggests the need for further detailed studies of this kind, not simply in relation to the social construction of different sleep problems in the media over time, but in relation to different types and genres of media, including new media, and in terms of both production and audience reception issues.

\section{Notes}

1. Thanks to Peter Conrad for clarification of these issues.

2. We place the term 'broadsheet' in quotes, given that paper sizes have now changed.

3. There was a further pragmatic rationale for this choice of search terms, given that the search criteria 'anywhere' yielded hits ranging from 244 to $1000+$ per article for insomnia and 353 to 601 per article for snoring.

4. Thanks to one of the anonymous reviewers for drawing this comparison to our attention.

\section{References}

Abraham, J. (1999). Therapeutic nightmare: The battle of the world's most controversial sleeping pill. London: Earthscan.

Blech, J. (2006). Inventing disease and pushing pills. London: Routledge.

Bury, M. and Gabe, J. (2006). Trial by the media. In D. Kelleher, J. Gabe and G.H. Williams (Eds.), Challenging medicine, 2nd edn, pp. 62-84. London: Routledge.

Conrad, P. (2005). The shifting engines of medicalisation. Journal of Health and Social Behavior, 46(March), 3-14.

Conrad, P. (2007). The medicalisation of society. New York: Johns Hopkins University Press.

Gabe, J. and Bury, M. (1996). Halcyon nights: A sociological account of a medical controversy. Sociology, 45(1), 227-69.

Hislop, J. and Arber, S. (2003a). Understanding women's sleep management: Beyond medicalisation-healthicisation. Sociology of Health \& Illness, 25(7), 815-37.

Hislop, J. and Arber, S. (2003b). Understanding women's sleep management: Beyond medicalisation-healthicisation: A response to Simon Williams. Sociology of Health \& Illness, 26(4), 460-3.

Kroll-Smith, S. (2003). Popular media and 'excessive daytime sleepiness': A study of rhetorical authority in medical sociology. Sociology of Health \& Illness, $25(6), 625-43$.

Moynihan, R., Heath, I. and Henry, D. (2002). Selling sickness: The pharmaceutical industry and disease mongering. British Medical Journal, 324(13 April), 886-91.

Rose, N. (1990). Governing the soul. London: Routledge.

Seale, C. (2004). Media and health. London: Sage Publications.

Seale, C., Boden, S., Williams, S.J., Lowe, P. and Steinberg, D.L. (2007). Media constructions of sleep and sleep disorders: A study of UK national newspapers. Social Science and Medicine, 65(3), 418-30. 
Williams, S.J. (2002). Sleep and health: Sociological reflection on the dormant society. health: An Interdisciplinary Journal for the Social Study of Health, Illness and Medicine, 6(2), 173-200.

Williams, S.J. (2003). Beyond medicalisation-heathicisation? A rejoinder to Hislop and Arber. Sociology of Health \& Illness, 26(4), 453-9.

Williams, S.J. (2005). Sleep and society: Sociological ventures into the (un)known. London: Routledge.

Woloshin, S. and Schwartz, L.M. (2006). Giving legs to restless legs: A case study of how the media help make people sick. Public Library of Science-Medicine, 3(4), 170-8.

\section{Author biographies}

SIMON WILLIAMS is a professor of sociology at the University of Warwick. He has published widely in the fields of health, medicine and the body, including a variety of recent research on sleep and society. He also has newly emerging research interests in biopolitics and neuropolitics, particularly in relation to psychopharmaceuticals and selfhood.

CLIVE SEALE is a professor of sociology at Brunel University who uses a variety of methods to investigate health topics, including studies of communication in medical settings, medicine and the media and end-of-life care. His books include Constructing death (Cambridge University Press, 1998), Media and health (Sage Publications, 2002) and Researching society and culture (Sage Publications, 2004). He is currently developing a new method for analysing texts for social research purposes called Comparative Keyword Analysis.

SHARON BODEN is a lecturer in sociology at Keele University. Her current research interests lie in the sociology of consumption, gender and sexuality. Previous research has investigated the identities of children/tweenagers as fashion consumers, the commercialization of the contemporary wedding and media representations of sleep and the bedroom.

PAM LOWE is a lecturer in sociology in the School of Languages and Social Sciences, Aston University. She has a broad interest in the sociology of the body including women's reproductive health, violence against women and sexuality. She is also currently engaged in work on the sociology of sleep.

DEBORAH LYNN STEINBERG is a reader in the Department of Sociology. Her research interests cross over cultures of science, gender and media studies. Her publications include: Bodies in glass: Genetics, eugenics, embryo ethics; Mourning Diana: Nation, culture and the performance of grief (with A. Kear); and Blairism and the war of persuasion (with R. Johnson). 